\title{
PRE-PROCESSES FOR URBAN AREAS DETECTION IN SAR IMAGES
}

\author{
Ş. Altay Açar ${ }^{\mathrm{a}}$, Ş. Bayır ${ }^{\mathrm{b}}$ \\ ${ }^{a}$ KBU, Faculty of Technology, Department of Mechatronics Engineering, Karabuk, Turkey - safakaltay@karabuk.edu.tr \\ ${ }^{\mathrm{b}} \mathrm{KBU}$, Faculty of Engineering, Department of Computer Engineering, Karabuk, Turkey - safakbayir@karabuk.edu.tr
}

KEY WORDS: Pre-process, Urban Areas Detection, Synthetic Aperture Radar

\begin{abstract}
:
In this study, pre-processes for urban areas detection in synthetic aperture radar (SAR) images are examined. These pre-processes are image smoothing, thresholding and white coloured regions determination. Image smoothing is carried out to remove noises then thresholding is applied to obtain binary image. Finally, candidate urban areas are detected by using white coloured regions determination. All pre-processes are applied by utilizing the developed software. Two different SAR images which are acquired by TerraSAR-X are used in experimental study. Obtained results are shown visually.
\end{abstract}

\section{INTRODUCTION}

Information of urban areas are very important for civilian and military applications. When the relevant literature is taken into consideration, it is seen that many academic studies are made on urban areas detection in SAR images. One of them presents an unsupervised urban area extraction method which is adaptive and iterative (He et al., 2006). In the other approach, two new data fusion methods are proposed and applied to detect small urban areas (Gouinaud, 2008). A research presents an improved method for extraction of urban area in high resolution and very high resolution SAR images (Gamba et al., 2011). A novel urban area extraction method based on an iterated foreground/background separation framework is proposed (Wang et al., 2011). In the other study, SAR image is classified as water, urban and land areas by utilizing a Bayesian model (Kayabol, and Zerubia, 2012). There are some approaches which are using polarimetric SAR images to detect urban and built-up areas (Kajimoto and Susaki, 2013; Yang et al., 2014; Azmedroub and Ouarzeddine, 2015). A convolution neural network based built-up areas detection method is presented $(\mathrm{Li}$ et al., 2016). Other research proposes a method to extract builtup areas by using SAR image's features (Yang et al., 2017).

Urban areas appear brighter than their neighbours in SAR image. Three different pre-processes for urban areas detection are examined by using this information in this study.

\section{PRE-PROCESSES}

Three pre-processes are applied to detect candidate urban areas. These are image smoothing, thresholding and white coloured regions determinations.

\subsection{Image Smoothing}

There are noises in SAR images and these noises affect process of urban area detection negatively; therefore, image smoothing is carried out to remove noises. $5 \times 5$ Gaussian filter is applied to all pixels of SAR image one by one for this process. The filter is shown in Figure 1 and used equation is defined in Equation 1.

\begin{tabular}{|c|c|c|c|c|}
\hline 1 & 4 & 7 & 4 & 1 \\
\hline 4 & 16 & 26 & 16 & 4 \\
\hline 7 & 26 & 41 & 26 & 7 \\
\hline 4 & 16 & 26 & 16 & 4 \\
\hline 1 & 4 & 7 & 4 & 1 \\
\hline
\end{tabular}

Figure 1. Gaussian filter

$$
p_{(x, y)}=\sum_{j=1}^{25} \frac{p_{j} f_{j}}{273}
$$

In the equation, $\mathrm{p}_{(\mathrm{x}, \mathrm{y})}$ is the new value of relevant pixel's colour, $\mathrm{p}_{\mathrm{j}}$ is relevant pixel's neighbour and $\mathrm{f}_{\mathrm{j}}$ is filter's value.

\subsection{Thresholding}

After image smoothing, thresholding is applied to obtain binary image. In this image, white coloured regions have high probability to be an urban area. Used equation is defined in Equation 2.

$$
f\left(p_{(x, y)}\right)=\left\{\begin{aligned}
0, & p_{(x, y)} \leq 200 \\
255, & p_{(x, y)}>200
\end{aligned}\right.
$$

In the equation, $\mathrm{p}_{(\mathrm{x}, \mathrm{y})}$ is the value of relevant pixel and 200 is the threshold value.

\subsection{White Coloured Regions Determination}

After thresholding, white coloured regions determination is applied to detect candidate urban areas. A 20x20 pixels block is shifted on the binary image for this process. In every step, the block searches different region as shown in Figure 2.

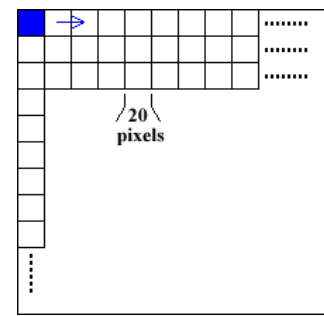

Figure 2. White coloured regions determination 
If binary image's region which corresponds to the block has at least $50 \%$ white colours, relevant region is accepted as a candidate urban area.

\section{EXPERIMENTAL RESULTS}

Two different SAR images (resolution: up to $2 \mathrm{~m}$, polarization: HH, mode: spotlight, multi look ground range) belonging to different regions are used for experimental study. They are acquired by TerraSAR-X. They have the same size (7000x7000 pixels). First region's urban areas and result are shown in Figure 3 and Figure 4. Second region's urban areas and result are shown in Figure 5 and Figure 6. Red ellipses denote urban areas in Figure 3 and Figure 5. White coloured regions denote candidate urban areas in Figure 4 and Figure 6.

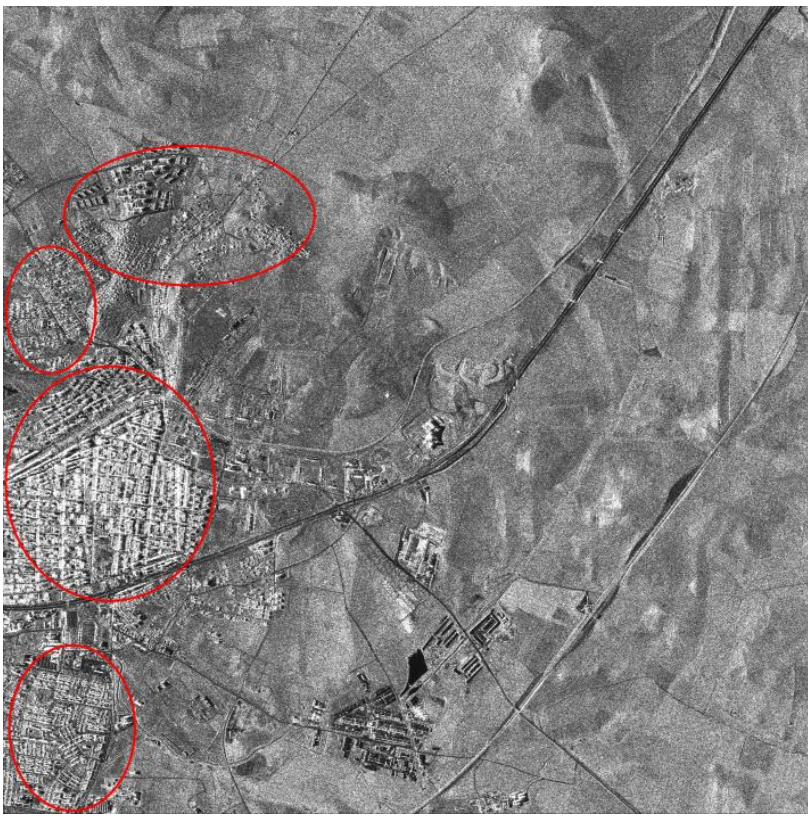

Figure 3. First region's urban areas

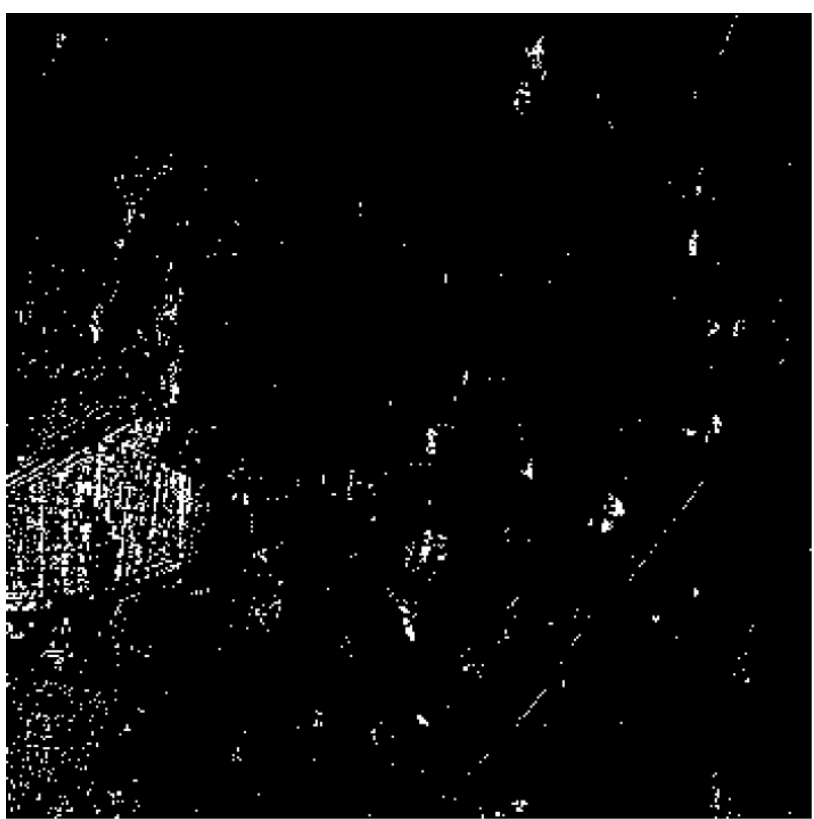

Figure 4. First region's result

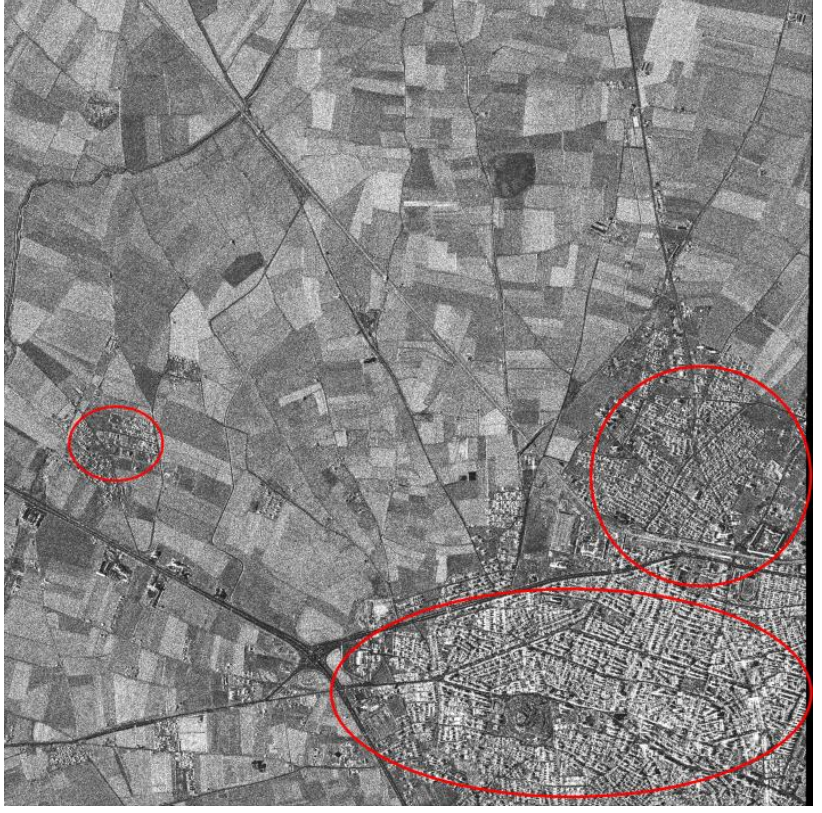

Figure 5. Second region's urban areas

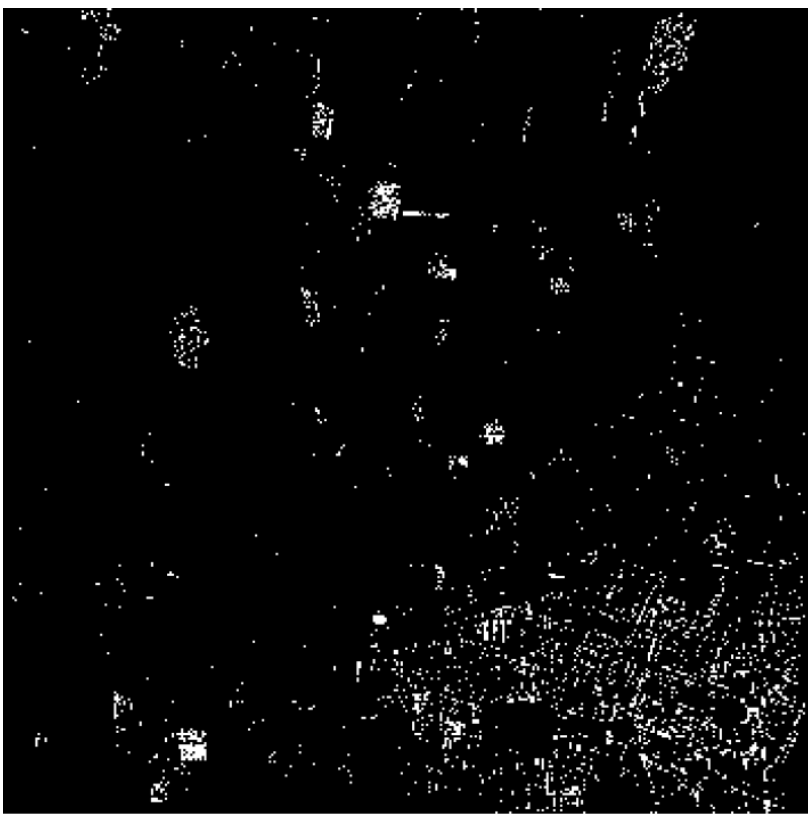

Figure 6. Second region's result

When we evaluate the results, we see that majority of urban areas are detected but some non-urban areas are detected, too.

\section{CONCLUSION}

In this study, pre-processes for urban areas detection in SAR images are examined. Three different pre-processes are applied to detect candidate urban areas in SAR images. Two different SAR images belonging to different regions are used for experimental study and obtained result are shown visually.

In the future, a fully automatic urban areas detection method will be improved by adding extra processes. 


\section{REFERENCES}

Azmedroub, B. and Ouarzeddine, M., 2015. Urban areas detection using polarimetric sar images. IEEE International Geoscience and Remote Sensing Symposium, Milan, Italy, pp. 3227-3230.

Gamba, P., Aldrighi, M. and Stasolla, M., 2011. Robust extraction of urban area extents in hr and vhr sar images. IEEE Journal of Selected Topics in Applied Earth Observations and Remote Sensing, 4(1), pp. 27-34.

Gouinaud, C., 2008. Sar image fusion in multi sensor context for small urban area detection. IEEE International Geoscience and Remote Sensing Symposium, Boston, USA, pp. 988-991.

He, C., Xia, C. and Sun, H., 2006. An adaptive and iterative method of urban area extraction from sar images. IEEE Geoscience and Remote Sensing Letters, 3(4), pp. 504-507.

Kajimoto, M. and Susaki, J., 2013. Urban-area extraction from polarimetric sar images using polarization orientation angle. IEEE Geoscience and Remote Sensing Letters, 10(2), pp. 337341.

Kayabol, K. and Zerubia, J., 2012. A comparison of texture and amplitude based unsupervised sar image classifications for urban area extraction. IEEE International Geoscience and Remote Sensing Symposium, Munich, Germany, pp. 4054-4057.

Li, J., Zhang, R. and Li, Y., 2016. Multiscale convolutional neural network for the detection of built-up areas in highresolution sar images. IEEE International Geoscience and Remote Sensing Symposium, Beijing, China, pp. 910-913.

Wang, H., Liu, B., Liu, X., Yu, W. and Jia C., 2011. Extraction of urban areas in $\mathrm{hr}$ sar images based on an iterated foreground/background separation framework. 3rd International Asia-Pacific Conference on Synthetic Aperture Radar, Seoul, South Korea.

Yang, W., Yin, X., Song, H., Liu, Y. and Xu, X., 2014. Extraction of built-up areas from fully polarimetric sar imagery via pu learning. IEEE Journal of Selected Topics in Applied Earth Observations and Remote Sensing, 7(4), pp. 1207-1216.

Yang, X., Yang, W., Zhong, N. and Liao, M., 2017. Extraction of build-up area from sar images using unsupervised ensemble learning. Joint Urban Remote Sensing Event, Dubai, UAE. 